Actas del Seminario Internacional Destinos Turísticos Inteligentes:

nuevos horizontes en la investigación y gestión del turismo

Universidad de Alicante, 26 y 27 de octubre de 2017

\title{
Las ciudades Patrimonio de la Humanidad ante el paradigma Smart
}

\section{Calle Lamelas, Juan Vicente}

Universidad Rey Juan Carlos, España

Doctorando en Turismo juanvicalle@gmail.com

\section{García Hernández, María \\ Universidad Complutense de Madrid, España Grupo de Investigación «Turismo, Patrimonio y Desarrollo» \\ Dpto. Geografía Humana mgarciah@ucm.es}

\section{García Muiña, Fernando}

Universidad Rey Juan Carlos, España

Dpto. Economía de la Empresa (ADO) Economía Aplicada Il y Fundamentos del Análisis Económico fernando.muina@urjc.es

"Como sucede con cualquier cambio tecnológico trascendental, los individuos, las empresas y las instituciones que lo experimentan en toda su intensidad se sienten abrumados por él, debido a que desconocen cuáles serán sus efectos.»

Manuel Castells

"La inteligencia consiste no sólo en el conocimiento, sino también en la destreza de aplicar los conocimientos en la práctica.»

Aristóteles

\section{Resumen}

La revolución digital está generando un conjunto de desarrollos tecnológicos que afectan a la experiencia turística y la transforman. Este fenómeno ha sido conceptualizado por literatura en inglés como smart tourism. A pesar de su importancia, es necesaria una mayor atención a su desarrollo teórico. En la literatura en español han recibido más atención otros conceptos como smart destination o destino turístico 
Actas del Seminario Internacional Destinos Turísticos Inteligentes:

nuevos horizontes en la investigación y gestión del turismo

Universidad de Alicante, 26 y 27 de octubre de 2017

inteligente, a su vez derivado de smart city. Con el foco puesto en la gestión pública del turismo en las ciudades Patrimonio de la Humanidad, este trabajo analiza la experiencia española de los destinos turísticos inteligentes y el proyecto Smart Heritage City que por primera vez aborda la gestión integral del patrimonio y los flujos de visitantes en una ciudad histórica (Ávila), aunando dos disciplinas normalmente distanciadas a pesar de su mutua dependencia.

\section{Abstract}

The digital revolution is generating a set of technological developments that converge on the tourist experience and transform it. This phenomenon has been conceptualized by literature in English as smart tourism. Despite its importance, more attention is needed to its theoretical development. In the literature in Spanish, more attention has been given to other areas of the phenomenon such as smart destinations or smart tourist destinations, which are themselves derived from smart city. Focusing on the public management of tourism in World Heritage Cities, this communication analyses the Spanish experience of Smart Tourism Destinations and the Smart Heritage City project which for the first time has addressed the integral heritage and visitor flow management, combining two normally distanced disciplines in spite of their mutual dependence.

Keywords: destino turístico inteligente, Smart Heritage City, Patrimonio de la Humanidad, smart tourism, ciudad histórica.

\section{Introducción}

España cuenta con 15 ciudades incluidas en la lista del Patrimonio Mundial de la UNESCO. Estas ciudades, agrupadas a través de una asociación para su promoción (Grupo Ciudades Patrimonio de la Humanidad de España, en adelante GCPHE), son importantes destinos turísticos que TURESPAÑA presenta como «destinos de referencia y visita obligada $»^{1}$. Se trata de ciudades pequeñas y medianas con una importante dependencia económica del turismo en muchos casos, lo cual convierte a este sector económico en estratégico. Su principal atractivo reside en los valores patrimoniales de la propia escena urbana, además de un amplio conjunto de elementos monumentales de especial relevancia a nivel histórico, artístico y turístico. En su conjunto constituyen un selecto club de ciudades que tienen grandes responsabilidades

1. http://ciudadespatrimonio.org/publicaciones/1416995999_Geo_espanol.pdf 
Actas del Seminario Internacional Destinos Turísticos Inteligentes:

nuevos horizontes en la investigación y gestión del turismo

Universidad de Alicante, 26 y 27 de octubre de 2017

de conservación y gestión patrimonial derivadas de su condición de «patrimonio mundial». Aunque con cifras de visitantes variables, se configuran como relevantes destinos de turismo cultural. Por ello la correcta gestión del patrimonio y los flujos de visita asociados se configuran como temas claves para la gestión pública local, tal y como recoge los documentos internacionales de turismo cultural (ICOMOS, 1993, 1999; Pedersen, 2005; UNESCO \& UNWTO, 1998; World Heritage Centre, 2015).

En esta escala, y dada la transversalidad del turismo, su correcta gestión y planificación afecta a muchos de los servicios públicos que presta la administración local dentro de las competencias que la ley le tiene otorgadas (Ley $7 / 1985$ ). Por otra parte, en este momento convergen demandas sociales de un gobierno más transparente y participativo, al cual se empieza a dar respuesta mediante soluciones de e-gobernanza, gobierno abierto y datos abiertos, digitalización de los servicios de las administraciones locales y rendición de cuentas (FEMP, 2016). Los turistas, ciudadanos en tránsito, también requieren y esperan ciertos servicios digitales (acceso internet, información turística, aplicaciones que ayuden a explorar los puntos de interés del destino, etc.). Aparecen también desarrollos tecnológicos que permiten enriquecer la experiencia del visitante o la gestión de flujos en destino (recomendación de itinerarios menos saturados, venta anticipada de entradas, etc.). Por su parte las empresas oferentes de servicios esperan que la administración coordine la promoción in situ de sus atractivos y mejorar así la rentabilidad de sus negocios. Estas son algunas de las coordenadas sobre las que se asienta la necesidad de buscar soluciones digitales o inteligentes (smart si utilizamos el concepto anglosajón predominante en el discurso) para mejorar la competitividad del destino, incluso gestionar su sostenibilidad, ya sea desde una aproximación más débil o más fuerte.

El concepto smart city surgió en los albores del siglo XXI, y está experimentado un crecimiento exponencial hasta convertirse para algunos autores en el nuevo paradigma de la planificación urbana (Komninos \& Tsarchopoulos, 2013), lo que lo ha situado en las agendas urbanas globales en tiempo récord. Autores como Hollands (2008) realizan una crítica casi en el albor del concepto, preguntándose dónde están las ciudades inteligentes del discurso corporativo e institucional. Más recientemente este autor (Hollands, 2015) vuelve a hacer una lectura crítica sobre la smart city ideal - comercial, la cual ha tenido pocos resultados prácticos y mucha confusión conceptual (Fernández González, 2015). En España el discurso institucional tiene herramientas 
Actas del Seminario Internacional Destinos Turísticos Inteligentes:

nuevos horizontes en la investigación y gestión del turismo

Universidad de Alicante, 26 y 27 de octubre de 2017

como el Plan Nacional de Ciudades Inteligentes lanzado en el año 2015 (PNCl), la Red Española de Ciudades Inteligentes creada en 2011 (RECl) con un total de 65 ciudades $^{2}$ y el trabajo de normalización llevado a cabo por AENOR. Los proyectos impulsados por el Plan Nacional y las experiencias de la RECl son de diversa índole y escala.

En este contexto resulta relevante analizar en la escala ciudad histórica la aplicación del concepto de smart city y sus derivados smart heritage city o destino turístico inteligente. Por tanto este artículo tiene como objetivo plantear cómo las soluciones creadas para la "gran smart city», se aplican a un tipo de ciudad de dimensiones más reducidas y con una trama urbana configurada en el pasado. El reconocimiento de los problemas propios de estos lugares con "Valor Universal Excepcional», los importantes desafíos en su conservación y gestión de la capacidad de carga son retos que se empiezan a abordar en algunas experiencias como la acción SUDOE «Smart Heritage City» que se desarrolla en Ávila entre 2016 y 2018. Desde el concepto global de smart city, a la gestión integral del patrimonio con soluciones tecnológicas de vanguardia del smart heritage, se revisa el estado del arte de los destinos inteligentes en su aplicación a la ciudad histórica turística (Ashworth \& Tunbridge, 1994; Calle Vaquero, 2002).

Este documento se estructura en cinco epígrafes. Tras la introducción, en el segundo epígrafe se presenta la metodología del trabajo. En el tercer apartado tras la aclaración de los significados del término anglosajón smart y su traducción al castellano como inteligente, se analiza smart tourism como concepto unificador de las importantes transformaciones que se vislumbran como consecuencia de la nueva oleada de tecnologías digitales con un impacto destacado en el turismo. En el cuarto epígrafe repasa los conceptos de smart city y sus derivados aplicados a los destinos turísticos en entornos urbanos patrimoniales (destino turístico inteligente y smart heritage city), recopilando algunas experiencias. Por último, se realiza un debate y conclusiones sobre el estado de implantación de los conceptos analizados en el GCPHE, así como alguna recomendación sobre la gestión de los flujos de visitantes en el proyecto SHcity de Ávila.

2. http://www.redciudadesinteligentes.es/sobre-la-red/quienes-somos/ampliar.php/Id_contenido/301/v/0/ 
Actas del Seminario Internacional Destinos Turísticos Inteligentes:

nuevos horizontes en la investigación y gestión del turismo

Universidad de Alicante, 26 y 27 de octubre de 2017

\section{Metodología}

La presente comunicación forma parte del trabajo de investigación doctoral sobre la gestión turística de las ciudades Patrimonio Mundial españolas en el contexto smart tourism. En la primera fase de la investigación se están delimitando los fundamentos del movimiento smart en la escala urbana ciudad histórica-turística y sus repercusiones en la gestión pública como destinos turísticos, que recae en organismos de gestión del destino, los Destination Management Organization (DMO). Dentro de este trabajo, se presenta un estado de la cuestión que pretende sintetizar la información de diversas fuentes secundarias, relacionando los constructos «ciudad histórica-turística» y «destino turístico inteligente» con las implicaciones en la gestión pública del turismo en Ciudades Patrimonio Mundial, a la vez que se explora el estado actual de aplicación y las primeras experiencias.

\section{Smart Tourism}

El concepto smart ha ido calando en muchas esferas de nuestra vida. La «inteligencia» se expande al igual que lo hace la información y las tecnologías que permiten la hiperconectividad mediante redes que crean una piel digital prácticamente ubicua (Rabari \& Storper, 2015). Un breve repaso a esta realidad permite reconocer diferentes escalas donde las "cosas» adquieren inteligencia mediante las TIC. Encontramos así algunos de los instrumentos más definitorios de nuestros tiempos como son teléfonos, relojes, coches, portátiles y tablets, wearables etc. Estos elementos conforman una escala humana y cotidiana, prolongaciones de nuestro cuerpo que potencian y $a$ priori facilitan nuestro día a día jugando un papel relevante en nuestros desplazamientos. El siguiente escalón en la jerarquía son los recintos que nos acogen y donde pasamos la mayor parte de nuestra vida (hogares, oficinas, alojamientos, edificios públicos como museos, teatros, infraestructuras de transporte), los cuales también transmiten, mediante redes de información y sensores, el pulso de los acontecimientos que registran. Todo ello se distribuye en un medio físico articulado en aglomeraciones urbanas. Las ciudades, en especial las grandes urbes de nuestro tiempo, conforman sistemas de gran complejidad donde ciudadanos habituales o temporales se concentran e interactúan. Sus actividades demandan un gran número de servicios y recursos que, para ser prestados correctamente precisan de una administración eficiente que logre satisfacer a los exigentes «homos urbanus». Del 
Actas del Seminario Internacional Destinos Turísticos Inteligentes:

nuevos horizontes en la investigación y gestión del turismo

Universidad de Alicante, 26 y 27 de octubre de 2017

smartphone tan importante en la experiencia del viaje (Google, 2016) a la gestión de la ciudad, el avance de soluciones inteligentes es imparable y la adopción por una buena parte de los ciudadanos con mayor ingresos e inquietud por viajar, hace que empresas y gobiernos tengan que adaptarse a este escenario de cambio constante hacia lo digital.

\subsection{Significado de smart y su traducción como inteligente}

El término smart se antepone a los términos city, heritage, heritage city, tourism, tourism destination, y es frecuente encontrar su traducción al castellano como «inteligente», perdiendo algunos de los matices de la palabra inglesa tal y como aparecen reflejados en las acepciones que recoge el www. thefreedictionary.com:

5. Capaz de hacer ajustes que se asemejan a los que resultan de decisiones humanas, principalmente por medio de sensores electrónicos y tecnología informática ${ }^{3}$

7 Capaz de realizar acciones independientes y aparentemente inteligentes $^{4}$

5. De acuerdo a la moda actual.

2. La facultad de pensar, razonar, adquirir y aplicar conocimientos ${ }^{5}$

1. Astuto, como en los negocio. Listo o brillante.

4. Bien cuidado.

El diccionario de la Real Academia Española (RAE), recoge en su quinta acepción de inteligencia una definición relacionada con las anteriores: «Dicho de un sistema, de un edificio, de un mecanismo, etc.: Que están controlados por computadora y son capaces de responder a cambios del entorno para establecer las condiciones óptimas de funcionamiento sin intervención humana».

Sin embargo, la traducción más habitual del término en castellano «inteligencia» se realiza al inglés como intelligence, y en relación con ello emergen

3. smart. (n.d.) American Heritage ${ }^{\circledast}$ Dictionary of the English Language, Fifth Edition. (2011). Retrieved May 92017 from http://www.thefreedictionary.com/smart

4. smart. (n.d.) WordNet 3.0, Farlex clipart collection. (2003-2008). Retrieved May 92017 from http://www.thefreedictionary.com/smart

5. smart. (n.d.) The American Heritage Roget's Thesaurus. (2014). Retrieved May 92017 from http://www.thefreedictionary.com/smart 
Actas del Seminario Internacional Destinos Turísticos Inteligentes: nuevos horizontes en la investigación y gestión del turismo

Universidad de Alicante, 26 y 27 de octubre de 2017

conceptos como Artificial Intelligence y Business Intelligence, muy relacionados con la revolución tecnológica objeto de estudio. Por ello, de alguna manera en lengua castellana pierde riqueza de significado la traducción literal de smart tourism como "turismo inteligente», pues tiene connotaciones diferentes producto del dominio del significado principal de inteligente. Para Albino, Berardi y Dangelico (2015) smart city es análogo de intelligent city, pero también de digital, virtual o ubicua. Sin embargo, otros autores apuntan que estos términos son más específicos y muestran niveles menos inclusivos que el término de smart cities (Caragliu et al., 2011; Townsend, 2013).

Encontramos pues una interpretación muy contextual del término inteligencia, donde smart para unos autores tiene un significado más holístico, amplio e integral que intelligent/intelligence. En otras ocasiones en conceptos como el de inteligencia artificial el significado es pleno pues la referencia es la inteligencia humana -test de Turing-, siendo ésta "la inteligencia suprema». Por tanto, es necesario aclarar qué es inteligente. Una referencia en este sentido puede ser la teoría de la inteligencia creadora de José Antonio Marina (2000). Para el filósofo español esta inteligencia sería «la capacidad de dirigir el comportamiento utilizando la información que capta y elabora ella misma, una inteligencia creadora que descubre posibilidades nuevas en la realidad, selecciona sus metas y las ejecuta, y que por tanto está encaminada a la acción. Podemos distinguir un "Yo ocurrente», que produce ocurrencias de forma involuntaria y espontánea, sin control, y un "Yo ejecutivo", que intenta dirigir y suscitar las ocurrencias, conoce la realidad e inventa posibilidades y fines, por eso es también un «Yo creador» que extrae y crea información voluntariamente». Realmente, es más próximo el concepto de inteligencia colectiva o el de inteligencia territorial (Territorial intelligence). La inteligencia territorial es definida por la European Network of Territorial Intelligence (ENTI)

"La inteligencia territorial es un medio para los investigadores, para los actores y para la comunidad territorial de adquirir un mejor conocimiento del territorio, pero también de controlar mejor su desarrollo. La apropiación de las tecnologías de la información y de la comunicación, y de la información en sí misma, es una etapa indispensable para que los actores introduzcan un proceso de aprendizaje que les permitirá obrar de manera pertinente y eficiente. La inteligencia territorial es particularmente útil para ayudar a los actores territoriales a proyectar, definir, animar y evaluar las políticas y 
Actas del Seminario Internacional Destinos Turísticos Inteligentes:

nuevos horizontes en la investigación y gestión del turismo

Universidad de Alicante, 26 y 27 de octubre de 2017

los acciones de desarrollo territorial sostenible» (Girardot, 2000; en Girardot, 2010, p. 26)

Otro concepto muy próximo es el de Intelligence Systems. Los sistemas inteligentes perciben el entorno mediante sensores y aprenden de las acciones que implementan para alcanzar metas específicas, son los sistemas de última generación que pueden ofrecer a consumidores y proveedores de servicios información más relevante para la toma decisiones, mayor movilidad y experiencias más satisfactorias, lo que debido a la complejidad de las decisiones en turismo es un campo óptimo para su uso (Gretzel, 2011).

Desde la perspectiva del turismo, la primera publicación oficial de la Organización Mundial del Turismo (UNWTO) sobre la materia, el documento final de la I Conferencia Mundial en Smart Tourism Destination (febrero de 2017 - Murcia), considera las soluciones smart como inteligentes sólo si mejoran la sostenibilidad (5.1 Smart solutions are only intelligent if they improve sustainability...). Para Li, Hu, Huang y Duan (2017) smart significa hacer lo correcto en diversas circunstancias complejas, siendo su significado más amplio y poniendo más énfasis en lo tecnológico. Utilizaremos preferentemente la terminología inglesa para smart city, smart tourism, smart heritage city/destination y preferentemente Destino Turístico Inteligente cuando nos refiramos a la aproximación hecha desde España. Evitaremos la expresión turismo inteligente.

\subsection{Smart tourism}

La palabra smart es un término de moda (buzzword) referente a desarrollos tecnológicos, económicos y sociales que utilizan las últimas tecnologías digitales everyware o ubicuas, que crean una piel digital hiperconectada, como sensores, internet de las cosas, big data, open data, cloud compunting (la nube), open API, RFID, NFC, GIS y sistemas de geoposicionamiento, beacons, entre otras, junto a nuevas formas de conectividad entre el hombre y las máquinas mutidispositivo (Gretzel, Sigala, Xiang, \& Koo, 2015; Gretzel, Zhong, \& Koo, 2016), así como la capacidad de responder a las demandas de los viajeros a través de asistentes virtuales (chatbots), soluciones de inteligencia artificial, machine learning y computación cognitiva.

El smart tourism es un fenómeno social surgido de la convergencia de las TIC con la experiencia turística (Hunter, Chung, Gretzel, \& Koo, 2015). Para Boes, Buhalis, \& Inversini (2015). El término smart es una palabra de 
Actas del Seminario Internacional Destinos Turísticos Inteligentes: nuevos horizontes en la investigación y gestión del turismo

Universidad de Alicante, 26 y 27 de octubre de 2017

marketing que abarca todo aquello embebido o mejorado por la tecnología y está muy centrado en la experiencia del usuario (Nam \& Pardo, 2011). Los últimos desarrollos de estas tecnologías están llamados a revolucionar aún más la forma de viajar. Pues, no sólo son los avances tecnológicos individuales e inconexos lo que genera inteligencia, sino también el uso concertado, interconectado y sincronizado de diferentes tecnologías (Gretzel, Sigala, et al., 2015). En la isla de Lanzarote, los Centros de Arte, Cultura y Turismo (CACT) del Cabildo, lanzaron en octubre de 2016 una aplicación pionera basada en computación cognitiva capaz de interaccionar con los visitantes a través de su lenguaje natural y responder a preguntas complejas en cuestión de segundos. Combina un gran conocimiento local junto a un conocimiento del visitante, que permite personalizar la experiencia. Un asistente personal virtual gracias a la utilización de beacons permite un suministro de información en función de un posicionamiento preciso. Para Elisa Martín, directora de tecnología e innovación de IBM España, este proyecto enlaza el mundo físico con la información que lo describe, dos mundos -el físico y el digitalque antes estaban desconectados 6 . Este tipo de apps manifiestan el potencial de aplicaciones creativas de las tecnologías asociadas a la revolución de la movilidad, en especial los smartphones como soporte de experiencias durante el viaje (Wang, Park, \& Fesenmaier, 2012). Todo ello constituye una etapa diferente denominada e-tourism (Buhalis, 2003), que no solo utilizaba tecnologías previas diferentes, sino que estaba principalmente centrada en el antes (planificación y reserva) y el después del viaje. Ahora, la revolución está en el mientras se viaja y no tanto en las decisiones tomadas fuera del lugar, por lo que las oportunidades de dar respuesta en tiempo real y totalmente personalizada abren un nuevo mundo de posibilidades a gestores de los destinos y negocios. Wearables, realidad aumentada/virtual con expectativas de desarrollo muy altas en el sector, permitirán desplazar los límites del tipo de datos que se recogen y como se utilizan, exhiben y experimentan (Gretzel et al., 2016).

En el ámbito smart tourism, a pesar de ser un fenómeno de gran relevancia, son escasos los trabajos académicos que abordan el concepto, tanto teórica como empíricamente (Gretzel, Koo, Sigala, \& Xiang, 2015). El gobierno chino, a través de la China National Tourism Administration (CNTA), declaró

6. https://www.smarttravel.news/2016/10/11/lanzarote-pionera-en-turismo-cognitivo-de-la-mano-de-ibm-watson/ 
Actas del Seminario Internacional Destinos Turísticos Inteligentes: nuevos horizontes en la investigación y gestión del turismo

Universidad de Alicante, 26 y 27 de octubre de 2017

el año 2013 como Year of Smart Tourism, y lo ha convertido en una importante iniciativa dentro de la política turística (Li et al., 2017). Estos autores recogen la definición de smart tourism en la Wikipedia china Baidu:

Smart tourism se refiere al uso de computación en la nube, redes y otras nuevas tecnologías mediante dispositivos portátiles con acceso a Internet, para conseguir información sobre recursos, empresas y actividades turísticas, etc. En ese sentido, los turistas pueden conseguir información puntual para organizar y modificar sus planes de viaje con el fin de hacer un uso inteligente y conveniente de todo tipo de información turística.

(http://baike.baidu.com/view/5217093.htm, 2012).

Para Gretzel et al. (2015) el término smart tourism surge a raíz de la difusión de nuevos avances en tecnologías de la información que ofrece novedosas formas de comunicación, recopilación, analítica e intercambio de datos, y de esta forma, nuevas oportunidades de creación de valor y gestión (Lazer et al., 2009). A partir de las tecnologías móviles de conectividad digital, este tipo de turismo aspira a crear conexiones más inteligentes, significativas y sostenibles entre los turistas y los destinos (Molz, 2012), cambiando hábitos de consumo y la experiencia turística.

Por tanto, hemos de enmarcar el smart tourism dentro de la gran transformación impulsada desde la economía digital, factor destacado de la cuarta revolución industrial (Schwab, 2016). Para el fundador del Foro de Davos, el profesor Klaus Schwab, la aparición de las nuevas tecnologías digitales está produciendo una revolución industrial más amplia, profunda y sistémica que las anteriores. En el sector turístico las TIC han tenido un notable impacto durante las últimas décadas debido al uso intensivo de información que realiza la actividad turística (Ivars Baidal, Solsona Monzonís, \& Giner Sánchez, 2016), favoreciendo su desarrollo a nivel global, al tiempo que ha logrado ser la primera industria en la creación de riqueza y empleo. Autores como Sheldon (1997) encuentran en la información "el alma del turismo», y las TIC la «columna vertebral de las operaciones turísticas».

Desde una concepción sistémica a la cual nos adherimos, surge el concepto relativo smart tourism ecosystem. Este se refiere a «sistemas turísticos que aprovechan la tecnología inteligente para crear, gestionar y entregar servicios / experiencias turísticos inteligentes, caracterizados por un intenso intercambio de información y co-creación de valor »(Gretzel, Werthner, Koo, \& Lamsfus, 2015, p. 560). En un reciente artículo publicado en Harvard 
Actas del Seminario Internacional Destinos Turísticos Inteligentes:

nuevos horizontes en la investigación y gestión del turismo

Universidad de Alicante, 26 y 27 de octubre de 2017

Business Review, Porter y Heppelmann (2014) sostienen que los productos «smart-connected» traerán una nueva era de competencia.

Gretzel, Sigala, et al. (2015) establecen tres componentes o ámbitos de aplicación que corresponden a los niveles de la experiencia del turista, los negocios y el destino (Smart Experience, Smart Business y Smart Destination). Cada nivel realiza procesos de captación, intercambio y procesamiento Big Data (fig.1), permitiendo la integración de la dimensión física y de gobernanza de la actividad turística. Estos novedosos planteamientos suponen alcanzar dimensiones no exploradas de inteligencia en los sistemas turísticos. El factor central del smart tourism son los datos, lo que Mayer-Schönberger \& Cukier (2013) denominan como el petróleo del siglo XXI, especialmente por su capacidad para fomentar el buen gobierno y el desarrollo económico. Estos autores apuntan a la datificación -el tener más datos de más aspectos del mundo- junto a tecnologías para procesarlos como un avance infraestructural que traerá consigo grandes cambios en la sociedad.
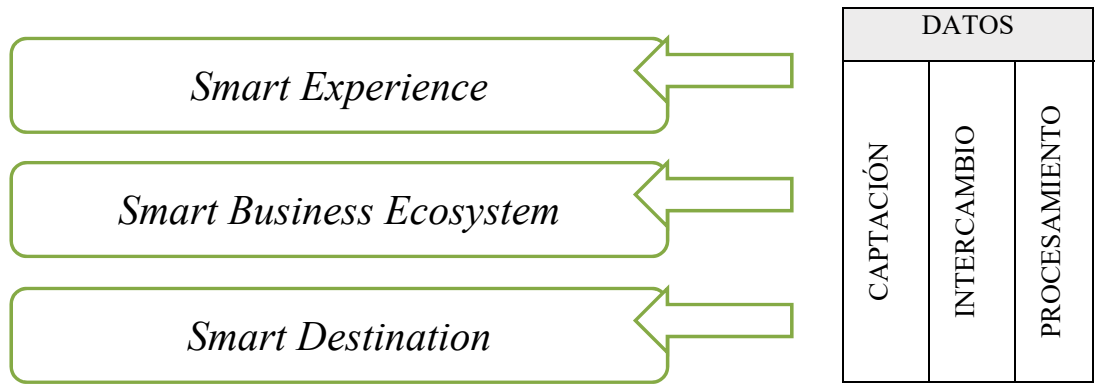

Fig. 1 Componentes y niveles del smart tourism. Fuente: Gretzel, Sigala et al. (2015)

Según Xiang \& Fesenmaier (2017) la última meta del smart tourism es dar soporte a la movilidad, la creatividad, la disponibilidad y distribución de recursos, la sostenibilidad y calidad de vida y visitas, a través de esfuerzos coordinados a gran escala e inversiones coordinadas en infraestructuras tecnológicas. Para ello los smart tourist destinations crean una info-estructura que se alimenta de los datos compartidos de forma activa y creativa o implícita por los consumidores.

Existe un apoyo por parte de las instituciones hacia el smart tourism, incluso en algunos casos hasta cierta presión (Gretzel, Sigala, et al., 2015; Mínguez García \& Ruiz, 2014). En Asia, los gobiernos de China y Corea del 
Actas del Seminario Internacional Destinos Turísticos Inteligentes:

nuevos horizontes en la investigación y gestión del turismo

Universidad de Alicante, 26 y 27 de octubre de 2017

Sur han financiado iniciativas para desarrollar infraestructuras tecnológicas (Hwang, Park, \& Hunter, 2015), y en España el Plan Nacional Integral de Turismo 2012-2015 del Ministerio de Industria, Energía y Turismo, contemplaba el desarrollo de los Destinos Turísticos Inteligentes como medida principal para «establecer los mecanismos adecuados que permitan la rápida incorporación de las innovaciones con la definición de un marco homogéneo, que permita tecnificar los destinos turísticos de forma alineada a las tendencias de creación de Ciudades Inteligentes (Smart Cities)»(Secretaría de Estado de Turismo, 2012, p. 71).

\section{De Smart city a Destino Turístico Inteligente}

Muchas de las iniciativas de smart tourism en Europa surgen de proyectos de smart city (Gretzel, Sigala, et al., 2015). De hecho el concepto de Destino Turístico Inteligente o Smart Tourism Destination surge del de smart city resultado de la aplicación a una escala y ámbito diferente (García Hernández \& Troitiño Torralba, 2016; Ivars Baidal et al., 2016; Mínguez García \& Ruiz, 2014). En lo referente al espacio objeto de aplicación de los proyectos, se entiende que operan sobre áreas en común, aunque el destino turístico puede abarcar un espacio inferior al municipal o mayor al incluir varios municipios. La naturaleza transversal de la actividad turística hace que soluciones para los residentes de la ciudad favorezcan a los ciudadanos en tránsito y viceversa.

\section{1 ¿Qué es una smart city?}

Tanto a nivel institucional como académico son muchos los documentos que en poco tiempo han tratado de abordar este término confuso y ambiguo. En España, la línea institucional esta abanderada por la Red Española de Ciudades Inteligentes (RECl). Para RECl son ciudades inteligentes aquellas que disponen de un sistema de innovación y de trabajo en red que les permite dotarse de un modelo de mejora de la eficiencia económica y política permitiendo el desarrollo social, cultural y urbano. Como soporte de este crecimiento se realiza una apuesta por las industrias creativas y por la alta tecnología todo ello a través de planes estratégicos participativos que permitan mejorar el sistema de innovación local.

En la literatura académica nos encontramos una amplia variedad de definiciones, que muestran la falta de consistencia en un constructo operativo y 
Actas del Seminario Internacional Destinos Turísticos Inteligentes:

nuevos horizontes en la investigación y gestión del turismo

Universidad de Alicante, 26 y 27 de octubre de 2017

medible, incluso con hechos contradictorios de los que se interpreta como una smart city (Albino et al., 2015; Cavada, Hunt, Rogers, \& Hunt, 2014; Fernández González, 2015). Para autores como Komninos \& Tsarchopoulos (2013), la smart city es el nuevo paradigma de planificación y gestión urbana. Con un planteamiento novedoso, el concepto ha evolucionado desde la intersección de ciudad y tecnología (capital físico), a enfoques más centrados en las personas y aspectos sociales (capital social) y de gobernanza. Por tanto, alineado con los objetivos del desarrollo sostenible y mejorara la calidad de vida. Para ello utiliza la planificación estratégica y desarrolla políticas de sostenibilidad e innovación (Invattur, 2015; Macadar, Porto, \& Luciano, 2015). En esta línea Caragliu et al. (2011, p. 70) definen la smart city como "aquella ciudad cuyas inversiones en capital humano y social, así como en infraestructuras de transporte tradicionales y de TICs favorecen el crecimiento económico sostenible y una alta calidad de vida, con una sabia gestión de los recursos naturales a través de un gobierno participativo".

Visiones más criticas, cuestionan el discurso hegemónico de la visión corporativa (Hollands, 2008). Este discurso se ha generalizado en la agenda de las políticas urbanas como imaginario tecnológico desconectado de la realidad del funcionamiento de la vida en las ciudades (Fernández González, 2015). Este discurso ha conseguido posicionarse como asunto prioritario dentro de agendas de las políticas urbanas en un periodo muy breve de tiempo, donde la industria tecnológica global ha tenido un papel destacado desde su origen (Cavada et al., 2014). ${ }^{78}$

En otro orden de cosas, dado el consejo científico en la necesidad de adoptar cambios urgentes para reducir la huella ecológica y en especial el impacto de la vida en las ciudades, en línea con el objetivo 11 de desarrollo sostenible de la ONU - lograr que las ciudades y los asentamientos humanos sean inclusivos, seguros, resilientes y sostenibles-, nos parece pertinente realizar una mirada crítica desde el análisis económico y la teoría del management. Las corporaciones locales representan a sus ciudadanos y son organizaciones con una agenda de acción, incluso con planes de ciudad, de los cuales surgen en muchos casos las oficinas y proyectos de smart city. Este nivel estratégico de los ayuntamientos está condicionado por un mandato

7. http://www.redciudadesinteligentes.es/

8. IBM llego incluso a patentar el término de «smarter cities» el 4 de octubre de 2011 (Fernández González, 2015, p. 36) 
Actas del Seminario Internacional Destinos Turísticos Inteligentes:

nuevos horizontes en la investigación y gestión del turismo

Universidad de Alicante, 26 y 27 de octubre de 2017

que tendrá una orientación y compromiso con la ciudadanía determinado. Por ello, es útil someter a un marco teórico el tipo de enfoque de las políticas donde se ubicaría. Siguiendo a Rodríguez Fernández (2007), las políticas que dirigen la smart city pueden tener un carácter instrumental o estratégico, donde se persigue alcanzar ciertos beneficios de carácter económico o tener un carácter de smart city avanzada, que contempla todas las dimensiones de la sostenibilidad. Por consiguiente, la visión estratégica estaría relacionada con esta aproximación más instrumental que, desde la retórica corporativa, trata de influir en políticas y la retórica institucional. Esta visión tiene su propia literatura, siendo el centro de estudio de IBM una de las fuentes más destacadas.

IBM define smart city como una ciudad que crea un sistema instrumentalizado, interconectado e inteligente. Donde instrumentalizado se refiere a la sensorización de las actividades de la ciudad; interconexión a la red que recoge cada bit de la ciudad e inteligente a las aplicaciones predictivas que permiten decisiones más precisas (Amaranggana \& Buhalis, 2013). Más próxima a la visión pluralista, existe una corriente que aboga por la orientación con las personas en el centro, donde aún siendo alto el componente tecnológico, este será un medio al servicio de las personas. Por ello, De esta forma, en la ciudad inteligente el espacio urbano se convierte en una plataforma inteligente que requiere la participación de las personas en la toma de decisiones, las cuales disponen de mejor información (TELEFÓNICA, 2011) para comprender el propio entorno. Dado el imperante sesgo tecnológico de muchos de los proyectos de smart city (Townsend, 2013) resulta clave para el buen funcionamiento del sistema la combinación de talento, creatividad y ciudadanos inteligentes y bien informados con el objetivo de lograr una buena gestión de los recursos disponibles (Giffinger, Fertner, \& Kramar, 2007). Solo a partir del capital humano se pueden crear ciudades más inteligentes, pues las TIC automáticamente no lo crean (Albino et al., 2015; Hollands, 2008). En esta línea, Saskia Sassen apuntaba que «para que las tecnologías disponibles realmente alimenten las ciudades debemos añadir una dimensión que haga que la tecnología refleje el conocimiento de los habitantes de la ciudad ${ }^{9}$ » o la charla en TED de Kent Larson donde el director del grupo del MIT media Lab's Changing Places afirmaba que el principal

9. http://www.abc.es/sociedad/20130516/abci-premio-principe-asturias-sociologa201305152226.html 
Actas del Seminario Internacional Destinos Turísticos Inteligentes:

nuevos horizontes en la investigación y gestión del turismo

Universidad de Alicante, 26 y 27 de octubre de 2017

foco de atención tiene que estar en las personas, porque las ciudades son espacios para la gente ( $« B u t$ in the end, the main thing we need to focus on are people. Cities are all about people. They're places for people»). ${ }^{10}$

\subsection{El concepto de destino inteligente y su recorrido en España}

En un entorno caracterizado por el acrónomio VUCA (Volatility, Uncertainty, Complexity, Ambiguity), las disrupciones de lo digital, junto a una mayor preferencia por los destinos urbanos, entre otros factores provoca una serie de tensiones y desafíos que justifican la necesidad de una gestión local coordinada. En este contexto, los Destination Management Organization (DMO) u Organizaciones de Gestión de Destinos necesitan nuevos enfoques para acometer dicha gestión, ante lo cual el auge de los Destinos Turísticos Inteligentes (DTI) es una respuesta, aún no bien definida, a todos los cambios anteriormente expuestos (García Hernández \& Troitiño Torralba, 2016; Ivars Baidal et al., 2016; Sheehan, Vargas Sánchez, Presenza, \& Abbate, 2016).

Los nuevos enfoques de gestión responden a los siguientes objetivos (Ivars Baidal et al., 2016):

- Garantizar la calidad ambiental y la sostenibilidad de los destinos.

- Hallar nuevas vías de competitividad en el escenario turístico actual.

- Enriquecer y diferenciar las experiencias turísticas que ofrecen los destinos.

- Reforzar y comunicar los atractivos del territorio.

- Aprovechar la alta penetración de las tecnologías de la información y la comunicación (TIC) en la producción y el consumo turísticos.

España ha sido el primer país europeo en desarrollar a nivel institucional un modelo de DTI y en crear una norma pionera a nivel internacional. En 2012, el Plan Nacional Integral de Turismo 2012-2015 (PNIT) recogía dentro de la línea «ofertas y destinos» la medida n.o 11 de 28 denominada "Destinos Inteligentes: Innovación en la gestión de destinos». La Sociedad Mercantil Estatal para la Gestión de la Innovación y las Tecnologías Turísticas (SEGITTUR) -entidad dependiente de la Secretaria de Estado de Turismo y responsable de impulsar la innovación (I+D+i) en el sector turístico español tanto a

10. https://www.ted.com/talks/kent_larson_brilliant_designs_to_fit_more_people_in_ every_city/transcript?language $=$ en\#t-953903 
Actas del Seminario Internacional Destinos Turísticos Inteligentes:

nuevos horizontes en la investigación y gestión del turismo

Universidad de Alicante, 26 y 27 de octubre de 2017

nivel público como privado- ha liderado el proyecto y es la encargada de la gestión y creación de de los DTI. SEGITTUR hasta la fecha ha realizado una serie de acciones que podríamos clasificar en: a) I+D, conceptualización y normalización, b) promoción y divulgación c) asesoramiento y apoyo técnico. Las acciones de conceptualización y normalización se vienen desarrollando desde 2012 y engloban la conceptualización del sistema; el impulso de proyectos pilotos; la creación a su propuesta del subcomité de Destinos Turísticos Inteligentes dentro del Comité Técnico de Normalización AEN/CNT 178 de Ciudades Inteligentes cuyo objetivo es la normalización de los requisitos, indicadores y métricas y que ha conseguido la en abril de 2016 la aprobación por AENOR de la norma UNE 178501 de Sistemas de Gestión de un Destino Turístico Inteligente. También incluyen el desarrollo de un Sistema de Inteligencia Turística implantado en los destinos de Badajoz-Elvas y Las Palmas de Gran Canaria. Las acciones de promoción y divulgación incluyen entre otras la publicación de un libro blanco de Destinos Turísticos Inteligentes, jornadas técnicas y presentaciones en Ferias como FITUR, INTUR, organización de eventos como "Smart Destinations: claves para la competitividad turística» celebrado en Madrid en 2015, ser la secretaría técnica del «1st UNWTO World Conference on Smart Destinations» celebrada en febrero de 2017 en Murcia, entre otras acciones de promoción y divulgación del modelo. Por último las acciones de asesoramiento y apoyo técnico a destinos, incluye todas las acciones dirigidas a acompañar a los destinos en la implantación del modelo. Entre otras se encuentra la realización de informes de diagnóstico y planes de acción, trabajos de consultoría más allá de nuestras fronteras como en Cozumel (México) ${ }^{11}$.

Un hito relevante dentro del proyecto de SEGITTUR fue la aprobación de la Norma UNE 178501: Sistema de Gestión de un Destino Turístico Inteligente. Mediante esta norma de calidad, se establece «un marco homogéneo que permitiera tecnificar los destinos turísticos bajo el concepto de Destinos Inteligentes de forma alineada a las tendencias de creación de Ciudades Inteligentes, tal y como aparece recogido en el Plan Nacional Integral de Turismo (PNIT) y en el Plan Nacional de Ciudades Inteligentes» ${ }^{12}$. Según la Norma UNE 178501 un DTI es «un destino innovador, consolidado sobre una infraestructura tecnológica de vanguardia, que garantiza el desarrollo

11. www.segittur.es y www.destinosinteligentes.es

12. http://www.destinosinteligentes.es/ 
Actas del Seminario Internacional Destinos Turísticos Inteligentes:

nuevos horizontes en la investigación y gestión del turismo

Universidad de Alicante, 26 y 27 de octubre de 2017

sostenible del territorio turístico, accesible para todos, que facilita la interacción e integración del visitante con el entorno e incrementa la calidad de su experiencia en el destino, a la vez que mejora la calidad de vida del residente». El modelo de la norma y SEGITTUR cuenta con cuatro pilares fundamentales: tecnología, innovación, accesibilidad universal y sostenibilidad. En este modelo, los DMO son los más adecuados para asumir el rol de ente gestor del DTI. Este independientemente de su naturaleza será responsable de desarrollar e implementar una política de gestión para el destino turístico y establecer objetivos, metas y planes de acción vinculados con los cuatros ejes ya citados sobre los que se asienta un DTI: innovación, tecnología, accesibilidad y sostenibilidad.

Superada una primera etapa del proyecto donde se ha avanzado en la definición del concepto de DTI, testado en una serie de proyectos pilotos y aprobada la norma del sistema de gestión de los DTI, el actual ejecutivo quiere impulsar su implantación como modelo de referencia. En esa línea, el actual Ministro de Energía, Turismo y Agenda Digital, en su primera comparecencia en el Congreso de los Diputados para presentar las líneas maestras de su departamento, anunció el desarrollo de un Plan Nacional de Destinos Turísticos Inteligentes y el objetivo de potenciar un turismo sostenible y digital $^{13}$. Hasta la fecha, solamente Benidorm ha tenido avances en la implantación de la norma con la realización de un test previo a la certificación. En cuanto a los destinos adheridos al sistema, actualmente aparecen en la web del proyecto 12 destinos nacionales y 2 mejicanos. La tabla 2, resume los tipos de acciones realizadas por ahora, en su mayoría puramente tecnológicas como dotar de WiFi (66\% de los destinos), o apps (50\%). El 100\% de los proyectos han realizado un diagnóstico de situación previo sobre el que se propone un plan director - hoja de ruta para su conversión en destino turístico inteligente.

En cuanto a sistemas de inteligencia competitiva, hay que destacar la puesta en marcha del Sistema de Inteligencia Turística (SIT) operativo desde 2015 en los destinos Badajoz-Elvas y Las Palmas de Gran Canaria. El SIT es una herramienta de análisis exhaustivo de distintas fuentes de información seleccionadas en función de las necesidades y particularidades del destino. El desarrollo del SIT ha sido realizado en exclusiva por SEGITTUR, utilizando

13. http://www.lamoncloa.gob.es/serviciosdeprensa/notasprensa/minetur/Paginas/2016/131216-nadal.aspx 
Actas del Seminario Internacional Destinos Turísticos Inteligentes:

nuevos horizontes en la investigación y gestión del turismo

Universidad de Alicante, 26 y 27 de octubre de 2017

tecnologías big data y business intelligence de última generación y software libre (Pentaho). El sistema es capaz de "cargar, procesar y analizar información que trasforma en conocimiento de utilidad, relevante, sistematizado y ordenado, para ponerlo al servicio del gestor del destino y todos los actores del mismo» (SEGITTUR, 2016). Respecto a la sostenibilidad, salvo el caso de los destinos mejicanos que tienen una política turística y planes estratégicos más alineados con este objetivo, tenemos que hablar de una escasa representación de dos destinos españoles que manifiesten estar trabajando en esta dirección. Son el caso de el Valle de Arán y Lloret del Mar. El primero certificado por Biosphere y el segundo con planes estratégicos y operativos sectoriales alineados con el modelo de competitividad sostenible reflejado en el Plan estratégico de turismo de Cataluña 2013-2016.

Uno de los escollos para la puesta en marcha del proyecto DTI la falta de financiación por parte de la Secretaría de Estado, pues corresponde al destino encontrar vías de financiación que permitan materializar plan de acción a través del Plan Nacional de Ciudades Inteligentes, Emprendetur (Ministerio de Industria, Energía y Turismo) o los fondos FEDER de la Unión Europea.

En el nivel autonómico, la Comunidad Valenciana, a través de INVATTUR -el equivalente a SEGITTUR en esta comunidad autónoma-, dentro de las acciones de inteligencia competitiva ha desarrollado el proyecto «Destinos Turísticos Inteligentes Comunitat Valenciana», junto al Instituto de Investigaciones Turísticas de la Universidad de Alicante. Destaca el Manual Operativo para la configuración de los DTI que incluye un modelo de referencia y una herramienta de autodiagnóstico. Este autodiagnóstico se estructura en los siguientes ámbitos del modelo DTI: Gobernanza, Sostenibilidad/Accesibilidad, Conectividad/Sensorización, Sistema de información /Inteligencia turística, Innovación, Información Turística y Marketing online.

Observamos como lentamente los DTIs se convierten en un nuevo paradigma para la planificación y gestión de los destinos turísticos. Ahora bien existe una brecha importante entre el discurso público dominante y la realidad de la intervención en destino, necesitada aún de una visión integral e integradora por ámbitos y niveles de trabajo tal como proponen Ivars et al. (2016) fig. 2. 
Actas del Seminario Internacional Destinos Turísticos Inteligentes: nuevos horizontes en la investigación y gestión del turismo

Universidad de Alicante, 26 y 27 de octubre de 2017

\begin{tabular}{|c|c|c|c|c|c|c|c|c|c|c|c|c|c|}
\hline DESTINO & \begin{tabular}{c|} 
Wifi \\
gratuita
\end{tabular} & \begin{tabular}{|l} 
Monitoriza- \\
dón WI FI \\
\end{tabular} & A pp desting & Web & $\mathbf{s} \mathbf{T}$ & $\begin{array}{c}\text { Formación } \\
\text { sector }\end{array}$ & $\begin{array}{c}\text { Datos } \\
\text { abiertos }\end{array}$ & Beacons & $\begin{array}{c}\text { Plan } \\
\text { director }\end{array}$ & $\begin{array}{c}\text { Colaboración } \\
\text { pública-privada }\end{array}$ & P. Accesibilidad & Sostenibilidad & Otros \\
\hline Almeria & $\mathrm{x}$ & & $\mathrm{x}$ & & & $\frac{x}{x}$ & & & 2015 & & & & \\
\hline Badaj oz & $\mathrm{x}$ & & $\mathrm{x}$ & & $\mathrm{x}$ & $\mathrm{x}$ & & & $\mathrm{x}$ & & & & \\
\hline Castelldefels & $\mathrm{x}$ & & $\mathrm{x}$ & & & & & & 2013 & & & & \\
\hline Cozumal (Mẹico) & & & & & & & & & 2015 & $\mathrm{x}$ & & \begin{tabular}{|l|} 
Plan de Turismo \\
Sustentable (2012- \\
2034) \\
\end{tabular} & $\begin{array}{l}\text { Orupos de trabajo } \\
\text { intersectoriales, investigación } \\
\text { de Universidad - División } \\
\end{array}$ \\
\hline El Hiarro & $\bar{x}$ & & $x$ & & & $x$ & & & & & & & \\
\hline Jaca & & & & & & & & & 2016 & & & & \\
\hline $\begin{array}{c}\text { Las Palmas de Gral } \\
\text { Canaria }\end{array}$ & $\mathrm{x}$ & & & & $\mathrm{x}$ & & $\mathrm{x}$ & App comercio & 2014 & & & & \\
\hline Lloret del Mar & $\mathrm{x}$ & & & & & & & & & $x$ & $\mathrm{x}$ & & $\begin{array}{l}\text { Planificacíón estratégica y } \\
\text { mperativa }\end{array}$ \\
\hline Marbella & & & & & & & $\mathrm{x}$ & App Marbella & 2014 & & & & A genda Digital Marbella \\
\hline Región de M uraia & & & $\mathrm{x}$ & & & & & & 2014 & & & & Ente gestor autonómico \\
\hline Palma de Mallorca & $\mathrm{x}$ & $\mathrm{x}$ & & $\mathrm{x}$ & & & & & 2014 & & & & Smart Office \\
\hline Tequila (Méfico) & $x$ & $x$ & $\mathrm{x}$ & $x$ & & & & & 2016 & $x$ & & \begin{tabular}{|l|} 
Políficas sostenibilidad y \\
de conservación del \\
patrimonio
\end{tabular} & $\begin{array}{l}\text { Consejo de Desarrollo Integral } \\
\text { de Tequila }\end{array}$ \\
\hline Valle de A rán & & & & & & & & & 2015 & & & Certificado Biosphere & $\begin{array}{l}\text { Monitorización caudal dc los } \\
\text { ríos }\end{array}$ \\
\hline Villaj oyosa & & & & $\mathrm{x}$ & & & & & 2013 & & $\begin{array}{l}\text { Paneles inf. } \\
\text { Accesibles }\end{array}$ & & \\
\hline
\end{tabular}

Tabla 2. Acciones ejecutadas en los DTI de SEGITTUR. Elaboración propia a partir de www. destinosinteligentes.es

\section{El destino turístico inteligente: ámbitos y niveles de trabajo}

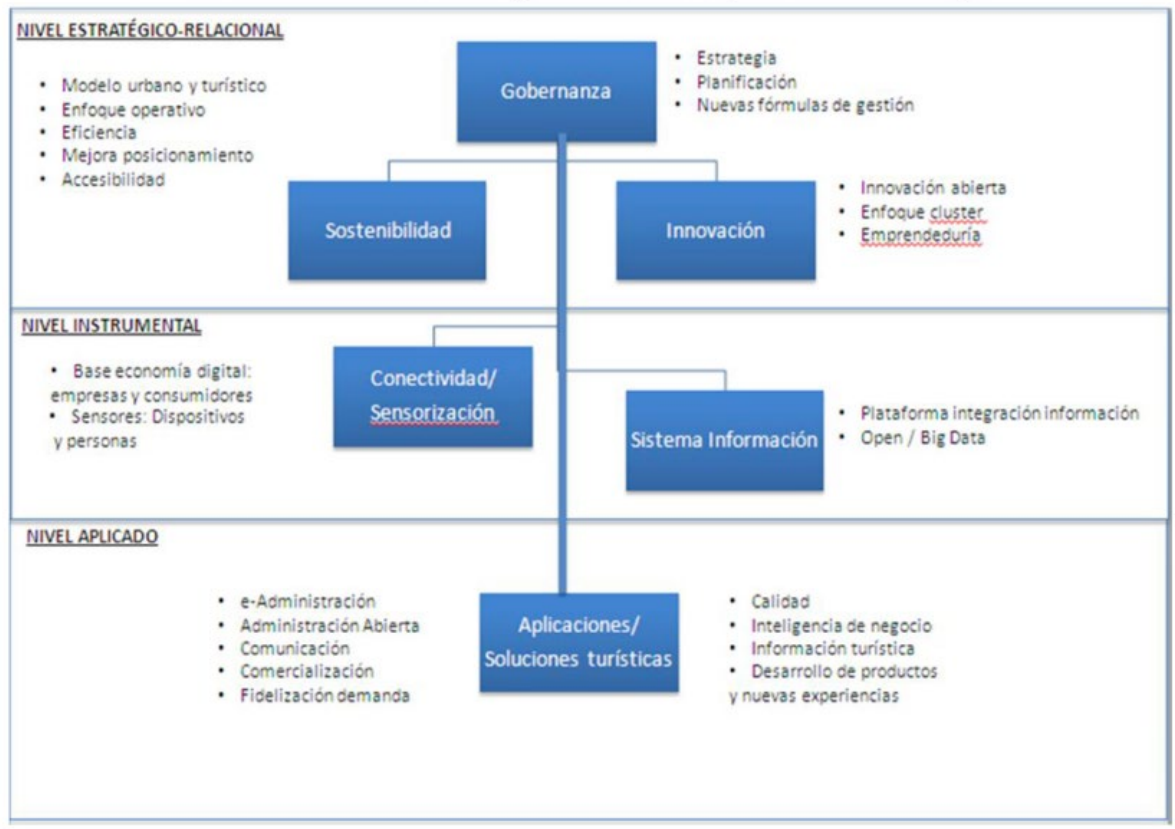

Fig. 2. Ámbitos y niveles del DTI (Ivars Baidal et al., 2016) 
Actas del Seminario Internacional Destinos Turísticos Inteligentes:

nuevos horizontes en la investigación y gestión del turismo

Universidad de Alicante, 26 y 27 de octubre de 2017

\subsection{Smart Heritage City}

Por último aparece en escena un nuevo concepto Smart Heritage City (SHcity). Este concepto se acuña en un proyecto del programa de cooperación transnacional de la Unión Europea Interreg SUDOE integrado por un grupo de instituciones del ámbito de la investigación y el patrimonio y el Ayuntamiento de la ciudad de Ávila. El programa tiene como objetivo crear una herramienta única de código abierto para la gestión de centros urbanos históricos con la intención de que pueda extrapolarse a otros conjuntos históricos europeos. La entidad coordinadora del proyecto es la Fundación Santa María la Real del Patrimonio Histórico (FSMLRPH). Esta fundación viene desarrollando en los últimos años una serie de iniciativas innovadoras para la conservación del patrimonio - Smart Patrimonio- y tiene una trayectoria de cuatro décadas en el estudio, restauración, conservación y difusión del Patrimonio. Smart Patrimonio es una de sus líneas de trabajo que tiene origen en la creación de un Sistema de Monitorización del Patrimonio (MHS) para la conservación preventiva y gestión integral de edificios. Surgió dentro del Plan Románico Norte y fue presentada como línea de trabajo en $2014^{14}$. La fundación cuenta con un laboratorio - MHSLab en la ermita románica de Santa María de Canduela (Palencia), con más de 50 sensores que monitorizan todas las pruebas que se realizan en el lugar, permitiendo su análisis y control en tiempo real. La fundación tiene como socio estratégico a Telefónica para la comercialización de esta solución tecnológica bajo el nombre de "Smart Patrimonio». Es una solución loT (internet de las cosas) adaptada al patrimonio histórico para registrar, evaluar y controlar diversos parámetros decisivos e influyentes en la conservación del edifico con el objetivo de asegurar la sostenibilidad de su gestión así como un óptimo mantenimiento del mismo y los bienes que alberga. A través de una red de sensores ambientales y estructurales permite realizar una gestión preventiva, pero también en materia de seguridad y protección, eficiencia energética y gestión de uso.

Otro antecedente de SHcity es el proyeto de I+D+I SHbuildings también del programa SUDOE y fondos FEDER. Este proyecto concluyó que estos sistemas de gestión integral pueden tener una reducción en los costes de conservación entre un 20 y un $50 \%$, por lo que permitiría mejorar notablemente

14. https://www.casadomo.com/2014/03/11/transforman-una-ermita-medieval-en-un-mhslab 
Actas del Seminario Internacional Destinos Turísticos Inteligentes:

nuevos horizontes en la investigación y gestión del turismo

Universidad de Alicante, 26 y 27 de octubre de 2017

la conservación, su uso y la visita pública de estos recursos patrimoniales ${ }^{15}$. El sistema (MHS) se ha implantado de forma satisfactoria en numerosos edificios patrimoniales como en las Catedrales de Ávila, Palencia y Ciudad Rodrigo, en la muralla de Ávila, y en el Real Monasterio de Santa Clara de Tordesillas, entre otros.

El proyecto de SHcity siguiendo la filosofía de las smart cities amplia la escala de monumentos o edificios aislados a la de espacios culturales o conjuntos monumentales. La solución SHcity integrará datos recogidos por una red de sensores (más de 300) distribuidos por el casco histórico de Ávila. Los datos son transformados en información útil que facilitará el trabajo de gestores y la toma de decisiones, permitiendo la previsualización en un modelo 3D y dos interface: uno de turistas y otro de gestores (fig 3). El sistema está diseñado para controlar y responder a los elementos de riesgo que afectan a los edificios y a su entorno cercano, la gestión de consumos energéticos y el control y ordenación del flujo de visitantes. Para la monitorización del flujo de visitantes se dedicarán 21 cámaras de conteo, que permitirán conocer con gran precisión cuales son los puntos de mayor afluencia de visitantes.

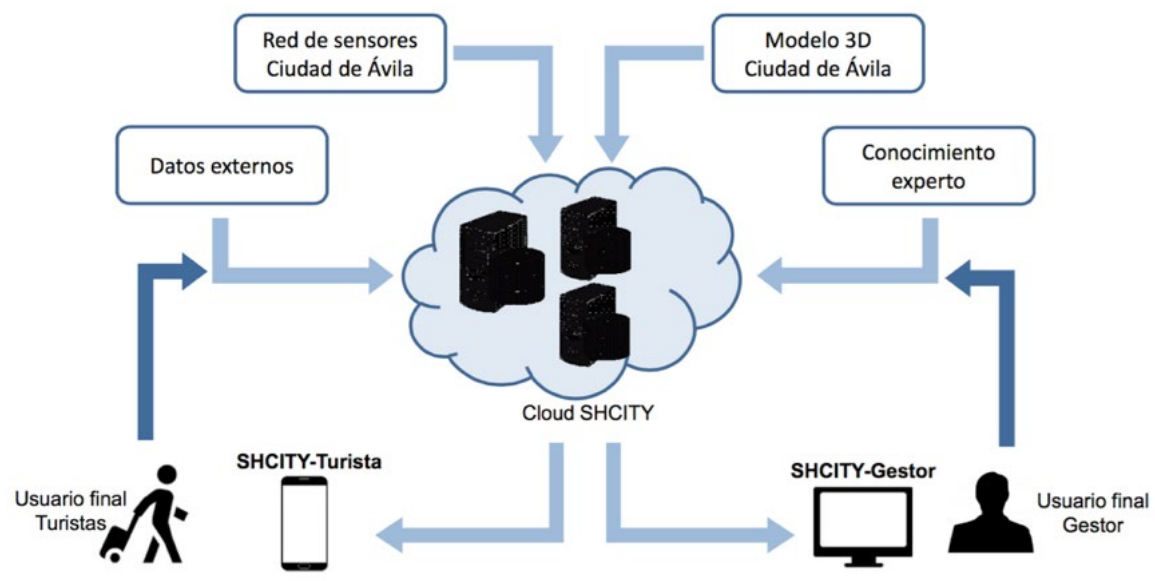

Fig. 3. Proyecto SHcity. Fundación SMLRPH (2017)

15. http://www.shbuildings.es/publicaciones_detalle.asp?id=408 
Actas del Seminario Internacional Destinos Turísticos Inteligentes:

nuevos horizontes en la investigación y gestión del turismo

Universidad de Alicante, 26 y 27 de octubre de 2017

\subsection{La ciudad histórica como destino turístico inteligente}

La gestión turística local no es indiferente al debate expuesto pues, dada la complejidad de los destinos turísticos, se asume que el enfoque de gestión está relacionado con la forma de conceptualizarlos (Ivars Baidal et al., 2016; Pearce, 2014). Las ciudades históricas (Ashworth \& Tunbridge, 1994), tienen unas peculiaridades como destinos que deben estar presentes en su gestión: el patrimonio es seña de identidad urbana y base de su atractivo turístico, solo cabe definir el turismo a partir de la demanda, simplificación y selectividad de la mirada turística, diversidad de proveedores e impacto en la práctica totalidad de las dimensiones urbanas (Calle Vaquero, 2002, pp. 25-27). Otro aspecto especialmente relevante en esta tipología de destinos es su escala más reducida. Siguiendo la clasificación de la OMT \& ETC (2005, p. 5), la mayoría de CPHE son ciudades patrimoniales pequeñas, donde el patrimonio cultural -artefactos del pasado- es el producto cultural predominante. Su pequeña escala condiciona naturalmente el planteamiento de gestión y su conversión en ciudades/destinos inteligentes. Es evidente que sus necesidades y problemas diferirán frente a las grandes metrópolis. Por ejemplo, el Índice de Ciudades Inteligentes promovido por International Data Corporation (IDC) en 2011 tuvo en cuenta a ciudades españolas con una población superior a los 150.000 habitantes.

\begin{tabular}{|c|c|c|c|}
\hline Ciudad & Mención & Población & Superficie HA \\
\hline Córdoba & Historic Centre of Córdoba & 328.000 & 80,28 \\
\hline Alcalá de Henares & University and Historic Precint & 198.750 & 78,38 \\
\hline San Cristobal dela Laguna & & 152.843 & 60,38 \\
\hline Salamanca & Old City & 148.042 & 50,78 \\
\hline Tarragona & Archaeological Ensemble & 132.199 & 32,65 \\
\hline Cáceres & Old Town & 95.855 & 9 \\
\hline Santiago de Compostela & Old Town & 95.800 & 107,59 \\
\hline Toledo & Historic City & 83.334 & 259,85 \\
\hline Mérida & Archaeological Ensemble of Mérida & 59.049 & 30,77 \\
\hline Ávila & Old Town wiht its Extra-Muros Churches & 58.933 & 36,45 \\
\hline Cuenca & Historic Walled Town of Cuenca & 55.738 & 22,79 \\
\hline Segovia & Old Town and its A queduct & 53.260 & 134,28 \\
\hline Ibiza & Ibiza, Biodiversity and Culture & 49.975 & 11,23 \\
\hline Úbeda & aissance Monumental Ensembles of Ubeda y Baeza & 35.930 & $9 *$ \\
\hline Baeza & aissance Monumental Ensembles of Ubeda y Baeza & 16.163 & $9 *$ \\
\hline
\end{tabular}

Tabla 1. Elaboración propia a partir de INE 2014-2015 y UNESCO (http://whc.unesco.org/) La superficie protegida de Ubeda y Baeza es conjunta. 
Actas del Seminario Internacional Destinos Turísticos Inteligentes:

nuevos horizontes en la investigación y gestión del turismo

Universidad de Alicante, 26 y 27 de octubre de 2017

En el caso del GCPHE solamente 4 ciudades de las 15 fueron analizados en este estudio de referencia. Una misma cuestión puede impedir que sea viable económicamente y menos relevante en función de la escala, derivado de los costes asociados a la implantación del sistema, mantenimiento y potencial valor de las soluciones para el sitio. En la ciudad de Ávila, el ámbito de actuación objeto de estudio podría quedar limitado generalmente al espacio delimitado en la declaración de la UNESCO como zona protegida. Este puede coincidir con una parte de la ciudad-histórica turística, por su potencial interés. Aunque la literatura ha demostrado que la zona turística tiende a concentrarse en unos determinados puntos y lugares de confluencia por la relevancia de su significado e imagen iconográfica, denostando otros lugares de importancia cultural que permanecen a la sombra de los nodos principales (Donaire \& Galí, 2008).

El proyecto SHcity toma como referencia precisamente la zona protegida en la declaración de UNESCO y debido a la naturaleza del proyecto generará una herramienta de código abierto que se podrá implantar en otras ciudades de similares características. Por tanto, encontramos en este caso una solución smart city nacida para la escala y el contexto objeto de estudio. Precisamente, con la intención de llevar a cabo una gestión integral de su mayor atractivo, la propia ciudad patrimonial. La gestión y ordenación del flujo de visitantes es uno de sus objetivos. Además creará una app para los turistas. Es precisamente en este punto, donde este tipo de proyectos tiene una vinculación con los DTI, además de las múltiples posibilidades que ofrecen las últimos desarrollos $\mathrm{TCl}$ que permiten mejorar el acceso a la información en lugar y momento adecuado a través de dispositivos móviles que incluso permite personalizar la experiencia y de esta forma mejorar la interpretación del patrimonio (Caro Herrero, Luque, \& Zayas, 2015; Tilden, 2006). Por ejemplo, algo tan importante como la seguridad para el turismo estaría dentro de los objetivos de este proyecto mediante la protección al ciudadano y también la protección frente a robos o vandalismo ${ }^{16}$, pero también la gestión de accesos o mejora de la interpretación del patrimonio.

La gestión de uso de los espacios patrimoniales y la gestión del flujo de visitantes son dos áreas donde los proyectos smart están llamados a ofrecer soluciones para desafíos aún sin resolver relativos a la capacidad de acogida

16. http://www.elcorreodeburgos.com/noticias/innovadores/sistema-toma-pulso-casco-historico_137154.html 
Actas del Seminario Internacional Destinos Turísticos Inteligentes:

nuevos horizontes en la investigación y gestión del turismo

Universidad de Alicante, 26 y 27 de octubre de 2017

o la visita pública de elementos patrimoniales. En lo relativo a la capacidad de carga, es de notoria actualidad el fenómeno de rechazo al turismo de residentes o turismofobia como respuesta a la turistificación de ciertos destinos urbanos consagrados y masificados como Venecia, Barcelona, Amsterdam. Desde hace tiempo se viene insistiendo en la necesidad de una planificación y gestión adaptada a la capacidad de acogida en los destinos patrimoniales (García Hernández, 2003), para evitar los efectos negativos del turismo en el patrimonio cultural. Por ello la necesidad de gestionar los flujos se hace cada vez más patente. En esta línea encontramos algunas experiencias pioneras en España y Europa. El Ayuntamiento de Barcelona presentó en la Smart City Expo 2016 un proyecto piloto para conocer la distribución de sus flujos de visitantes en los alrededores de la Sagrada Familia ${ }^{17}$. En Benidorm, la aplicación Visit Benidorm por un lado permite a los visitantes mediante bluetooth recibir notificaciones cuando el usuario este cerca de los puntos de referencia a través de beacons en función de su perfil (edad, genero, lugares visitados, país, etc.), de esta forma llegan a aquellos visitantes que no tienen conexión a internet y de otra pueden conocer a través de los registros de actividad de la aplicación geoposicionados cómo los diferentes perfiles de visitantes recorren los diferentes atractivos. Pero incluso, a través de los móviles, podemos conocer el comportamiento de los visitantes en el interior de monumentos y museos. En esta línea, es interesante el estudio realizado en el museo del Louvre de distribución de visitantes y duración de la visita ${ }^{18}$. A escala país, Andorra y el MIT media lab han puesto en en marcha Andorra Living Lab con el objetivo de convertir Andorra en un país inteligente. Estudia los patrones de comportamiento de los turistas en su territorio y como afecta a la movilidad, empredimiento, diseñando intervenciones que mejoren la experiencias de los turistas para fidelizar y aumentar gasto y duración de estancia. Dentro de los proyectos, se trabaja en un sistema de recomendación basado en localización a partir del análisis de registros de teléfono y redes sociales ${ }^{19}$. Estas primeras experiencias tienen en común la utilizan soluciones big data y datasets procedentes de los registros de tecnologías de comunicación WiFi, bluetooth y redes de telefonía móvil. Ofreciendo información de puntos de entrada y salida en un área delimitada o

17. http://www.ajuntamentbarcelonapremsa.info/download/oitbigsagfamilia.pdf

18. http://senseable.mit.edu/louvre/

19. www.cities.media.edu/andorra-tourism 
Actas del Seminario Internacional Destinos Turísticos Inteligentes:

nuevos horizontes en la investigación y gestión del turismo

Universidad de Alicante, 26 y 27 de octubre de 2017

destino, recorridos, duración de la visita, que se pueden combinar con lugar de procedencia, variables demográficas y preferencias mostradas al crear el perfil en el caso de apps. Además, la granularidad de la información permite conocer el detalle de lugar y momento donde se producen. Por tanto, permiten alcanzar un nivel de conocimiento de la actividad turística a escala local, y con ello suponen una base de conocimiento esencial para la toma de decisiones (Calle Lamelas, 2016). Los gestores pueden organizar mejor servicios urbanos y de atención al visitante de acuerdo al conocimiento de la demanda, además de la gran capacidad predictiva que permitiría ajustar mejor los servicios, incluso recomendar alternativas a los visitantes.

\section{Discusión y conclusiones}

De un tiempo a esta parte todo recibe el apelativo de smart. Esto es resultado de una tecnología que de manera imperceptible se imbrica en los objetos y les brinda nuevas capacidades, permitiendo recoger e intercambiar datos antes aislados y ahora conectados a la red de redes: internet. El internet de las cosas conecta objetos de todo el mundo de forma inteligente y sensorial. En todos los sitios y en cualquier momento (Everywhere \& everytime). De esta forma, el mundo se digitaliza y puede ser conocido al instante. La información para la toma decisiones es más relevante tanto para gestores como para turistas, facilitando mejores experiencias y una gestión más inteligente. Los datos son claves en la co-creación de valor y están en el centro de todas las actividades del smart tourism (Gretzel, Sigala, et al., 2015).

Si la literatura internacional ha abordado escasamente el concepto smart tourism, en español es todavía más reducido el número de trabajos dedicados a este concepto hasta la fecha. La traducción al español de smart se realiza habitualmente como inteligente, perdiendo algunos de los significados que tiene en inglés. Por ello, depende de la adopción que se realice del concepto y su realidad. Por ejemplo, los destinos turísticos inteligentes debido al trabajo institucional persistente por parte de SEGITTUR o INVATTUR transmiten mejor el amplio significado del concepto. Pues precisamente la aproximación a la gestión de estos destinos engloba sostenibilidad -de por sí un término muy ambicioso y con ciertas dificultades para su medición-, accesibilidad, tecnologías e innovación. Sucede lo mismo con las ciudades inteligentes, donde España tiene una posición de liderazgo por el número de iniciativas. Sin embargo, se tiende a utilizar smart heritage o incluso smart patrimonio. Así que hemos utilizado los términos en inglés en 
Actas del Seminario Internacional Destinos Turísticos Inteligentes: nuevos horizontes en la investigación y gestión del turismo

Universidad de Alicante, 26 y 27 de octubre de 2017

aquellos contextos donde la práctica y literatura tiene pocos avances en los países de habla hispana. Se propone además frente a la crítica de smart city corporativa dos tipos de smart city la instrumental o estratégica -centrada en la eficiencia- y la avanzada para aquella que tiene una visión que contempla todas las dimensiones de la sostenibilidad y un mayor foco en las comunidades y personas.

Hasta ahora, son escasas las experiencias de DTI en el GCPHE (García Hernández \& Troitiño Torralba, 2016). Por esta razón, resulta singular el proyecto SHcity que permitirá la gestión del principal atractivo de las ciudades históricas-turísticas -el conjunto urbano- en una herramienta única de código abierto, adaptando por primera la escala de monitorización de un edificio a un conjunto urbano. Estos activos patrimoniales, por su valor excepcional, merecen contar con los últimos desarrollos tecnológicos para monitorizar su estado mediante una red de sensores que indiquen como evolucionan aquellas variables críticas para su conservación. Este carácter preventivo en su conservación permite dar una respuesta inmediata a posibles eventos críticos que pudieran causar daños mayores, reduciendo de manera considerable los costes de conservación. Hay que destacar que la «invisibilidad» de las nuevas soluciones tecnológicas, permiten intervenir en un campo tan restrictivo como es el del patrimonio. Además, se ha de destacar que contribuye al desarrollo sostenible mediante la gestión de consumos energéticos y ordenación de flujos de visitantes, aunando dos mundos que normalmente viven de espaldas la gestión patrimonial y el turismo, en un momento donde la presión hacia los conjuntos patrimoniales destacados aumenta y precisa de una planificación y gestión concertada entre las partes. La experiencia nace con la intención de replicarse en otras ciudades, siendo su coste más reducido y asumible al haberse testado su fase de I+D en este proyecto pionero y al ser una herramienta de código abierto. El prestigio de la FSMLRPH y las líneas de financiación existentes en cada momento serán también factores facilitadores. Su despliegue a otras ciudades patrimoniales se podrá ver frenado por las reticencias de los decisores como consecuencia de la aversión al cambio o apatía ante nuevas formas de gestionar el patrimonio, o en palabras de Castells (2013), al verse superadas por estos grandes cambios por la ignorancia de sus efectos. La inversión inicial puede ser otra barrera de entrada destacada, pues aunque los costes sean menores a este proyecto fruto del abaratamiento progresivo de estas tecnologías y los costes iniciales de desarrollo de la solución que se suponen no asumirán 
Actas del Seminario Internacional Destinos Turísticos Inteligentes:

nuevos horizontes en la investigación y gestión del turismo

Universidad de Alicante, 26 y 27 de octubre de 2017

los nuevos emplazamientos, siguen siendo inversiones importantes para ayuntamientos y propietarios de los activos patrimoniales con restricciones presupuestarias. De hecho, la carga de gestionar tan vasto legado es una de las reclamaciones del GCPHE. Aunque la medición del flujo de turistas en distintos puntos de la ciudad contribuirá al conocimiento con mayor precisión de cómo se distribuyen durante sus estancias los turistas, al no combinarse con otras tecnologías como las utilizadas en Barcelona o Benidorm no queda claro de que forma se va a logar "ordenar» esos flujos. Es necesaria la utilización creativa de tecnologías de recomendación para informar y recomendar al visitante zonas menos saturadas, puntos de interés con tiempos de espera más reducidos y visitas que se ajusten al perfil e intereses del turista. En definitiva, tomando el aforismo de Aristóteles, el reto se encuentra en que todas las posibilidades de analítica que ofrecen las nuevas tecnologías digitales, tras su posterior transformación en conocimiento, sean aplicadas en la práctica de forma inteligente.

La comunicación ha tratado de clarificar el significado de los smart en español. Pero, es necesario seguir avanzando en la base teórica y relaciones de los constructos analizados. Precisamente este es uno de los objetivos de la investigación doctoral. Para superar las limitaciones de esta comunicación está previsto utilizar técnicas cualitativas aún por definir como entrevistas semi-estructuradas o Delphi. En futuras investigaciones se tiene previsto realizar casos de estudio para conocer el grado de implantación en ciudades históricas de los constructos analizados.

\section{Referencias}

Albino, V., Berardi, U., \& Dangelico, R. M. (2015). Smart Cities: Definitions, Dimensions, Performance, and Initiatives. Journal of Urban Technology, 22(1), 3-21. http://doi.org/10.1080/10630732.2014.942092

Ashworth, G. J., \& Tunbridge, J. E. (1994). The Tourist-historic city. John Wiley.

Boes, K., Buhalis, D., \& Inversini, A. (2015). Conceptualising Smart Tourism Destination Dimensions. En I. Tussyadiah \& A. Inversini (Eds.), Information and Communication Technologies in Tourism 2015 (Vol. 28, pp. 391-403). Cham: Springer. http://doi.org/10.1007/978-3-319-14343-9_29

Buhalis, D. (2003). eTourism: information technology for strategic tourism management. Harlow [etc.]: Financial Times Prentice Hall.

Calle Lamelas, J. V. (2016). Big data y creación de conocimiento en los Destinos Patrimonio de la Humanidad de España. En Turitec 2016: XI Congreso internacional 
Actas del Seminario Internacional Destinos Turísticos Inteligentes:

nuevos horizontes en la investigación y gestión del turismo

Universidad de Alicante, 26 y 27 de octubre de 2017

de Turismo y Tecnologías de la Información y la Comunicación (pp. 136-150).

Málaga: Universidad de Málaga.

Calle Vaquero, M. de la. (2002). La ciudad histórica como destino turístico. Ariel.

Caragliu, A., Del Bo, C., \& Nijkamp, P. (2011). Smart Cities in Europe. Journal of Urban

Technology, 18(2), 65-82. http://doi.org/10.1080/10630732.2011.601117

Caro Herrero, J. L., Luque, A., \& Zayas, B. (2015). Nuevas tecnologías para la inter-

pretación y promoción de los recursos turísticos culturales. Revista de Turismo

y Patrimonio cultural, 13, 931-945.

Castells, M. (2013). El impacto de Internet en la sociedad: una perspectiva global. En

c@mbio: 19 ensayos fundamentales sobre como internet está cambiando nuestras vidas. Madrid: BBVA. Recuperado a partir de https://www.bbvaopenmind. com/wp-content/uploads/2014/03/BBVA-Comunicación-Cultura-Manuel-Castells-El-impacto-de-internet-en-la-sociedad-una-perspectiva-global.pdf

Cavada, M., Hunt, D. V. L., Rogers, C. D. F., \& Hunt, D. V. L. (2014). Smart Cities : Contradicting Definitions and Unclear Measures. En World Sustainability Forum 2014 (pp. 1-12). Basel, Switzerland: MDPI. http://doi.org/10.3390/wsf-4-f004

Donaire, J. A., \& Galí, N. (2008). Modeling tourist itineraries in heritage cities. Routes around the Old District of Girona. PASOS. Revista de Turismo y Patrimonio Cultural., 6(3), 435-449.

FEMP. (2016). Gobierno abierto. Recuperado a partir de http://femp.femp.es/ files/3580-1446-fichero/Victoria Figueroa.pdf

Fernández González, M. (2015). La smart city como imaginario socio-tecnológico.

La construcción de la utopía digital. Universidad del País Vasco. Recuperado a partir de http://hdl.handle.net/10810/19301

FSMLRPH. (2017). Presentación SHCity. Aguilar de Campoo.

García Hernández, M. (2003). Turismo y conjuntos monumentales : capacidad de acogida turística y gestión de flujos de visitantes. Tirant lo Blanch.

García Hernández, M., \& Troitiño Torralba, L. (2016). La transformación de la ciudad histórica en destino turístico Inteligente. En CETT (Ed.), Smart tourism congress Barcelona. Barcelona.

Girardot, J.-J. (2010). Inteligencia territorial y transición socio-ecológica. Trabajo: Revista andaluza de relaciones laborales, (23), 15-39.

Google. (2016). How people use their phones for travel. Recuperado a partir de https://storage.googleapis.com/think/docs/app-marketing-travel-consumer-journey.pdf

Gretzel, U. (2011). Intelligent systems in tourism: A Social Science Perspective. Annals of Tourism Research, 38(3), 757-779. http://doi.org/10.1016/j. annals.2011.04.014 
Actas del Seminario Internacional Destinos Turísticos Inteligentes:

nuevos horizontes en la investigación y gestión del turismo

Universidad de Alicante, 26 y 27 de octubre de 2017

Gretzel, U., Koo, C., Sigala, M., \& Xiang, Z. (2015). Special issue on smart tourism: convergence of information technologies, experiences, and theories. Electronic Markets, 25(3), 175-177. http://doi.org/10.1007/s12525-015-0194-x

Gretzel, U., Sigala, M., Xiang, Z., \& Koo, C. (2015). Smart tourism: foundations and developments. Electronic Markets, 25(3), 179-188. http://doi.org/10.1007/ s12525-015-0196-8

Gretzel, U., Werthner, H., Koo, C., \& Lamsfus, C. (2015). Conceptual foundations for understanding smart tourism ecosystems. Computers in Human Behavior, 50, 558-563. http://doi.org/10.1016/j.chb.2015.03.043

Gretzel, U., Zhong, L., \& Koo, C. (2016, mayo 3). Application of smart tourism to cities. International Journal of Tourism Cities. Emerald Group Publishing Limited. http://doi.org/10.1108/IJTC-04-2016-0007

Hollands, R. G. (2008). Will the real smart city please stand up? City:Analysis of Urban Trends, Culture, Theory, Policy, Action, 12(3), 303-320. http://doi. org/10.1080/13604810802479126

Hollands, R. G. (2015). Critical interventions into the corporate smart city. Cambridge Journal of Regions, Economy and Society, 8(1), 61-77. http://doi.org/10.1093/ cjres/rsu011

Hunter, W. C., Chung, N., Gretzel, U., \& Koo, C. (2015). Constructivist Research in Smart Tourism. Asia Pacific Journal of Information Systems, 25(1). http://doi. org/10.14329/apjis.2015.25.1.105

Hwang, J., Park, H.-Y., \& Hunter, W. C. (2015). Constructivism in Smart Tourism Research : Seoul Destination Image. Asia Pacific Journal of Information Systems, 25(1), 163-178. http://doi.org/10.14329/apjis.2015.25.1.163

ICOMOS. (1993). Tourism at World Heritage Sites: The Site Manager's Handbook. Washington: World Tourism Organization.

ICOMOS. (1999). Carta internacional sobre el turismo cultural. La Gestión del Turismo en los sitios con Patrimonio.

Invattur. (2015). Destinos turísticos inteligentes. Manual Operativo (Vol. 1).

Ivars Baidal, J. A., Solsona Monzonís, F. J., \& Giner Sánchez, D. (2016). Gestión turística y tecnologías de la información y la comunicación (TIC): El nuevo enfoque de los destinos inteligentes. Documents d'Anàlisi Geogràfica, 62(2), 327-346. http://doi.org/http://dx.doi.org/10.5565/rev/dag.285

Komninos, N., \& Tsarchopoulos, P. (2013). Toward Intelligent Thessaloniki: from an Agglomeration of Apps to Smart Districts. Journal of the Knowledge Economy, 4(2), 149-168. http://doi.org/10.1007/s13132-012-0085-8

Lazer, D., Pentland, A., Adamic, L., Aral, S., Barabasi, A.-L., Brewer, D., ... Tembe, W. (2009). Computational social science. Science (New York, N.Y.), 323(5915), 7213. http://doi.org/10.1126/science.1167742 
Actas del Seminario Internacional Destinos Turísticos Inteligentes:

nuevos horizontes en la investigación y gestión del turismo

Universidad de Alicante, 26 y 27 de octubre de 2017

Li, Y., Hu, C., Huang, C., \& Duan, L. (2017). The concept of smart tourism in the context of tourism information services. Tourism Management, 58, 293-300. http:// doi.org/10.1016/j.tourman.2016.03.014

Macadar, M. A., Porto, J. B., \& Luciano, E. (2015). Smart City : a rigorous literature review of the concept from 2000 to 2015. En H.J. Scholl et al (Ed.), Electronic Government and Electronic Participation (Vol. 0, pp. 203-210). Amsterdam: IOS Press. http://doi.org/10.3233/978-1-61499-670-5-203.

Marina, J. A. (2000). Teoría de la inteligencia creadora ( $8^{\circ}$ ed.). Barcelona: Editorial Anagrama.

Mayer-Schönberger, V., \& Cukier, K. (2013). Big data. Turner.

Mínguez García, C., \& Ruiz, P. (2014). Los destinos turísticos inteligentes en España: ¿Un proyecto institucional o el futuro del sector? En E. (ed.. Fernández Tabales, A. y Navarro-Jurado (Ed.), Espacios turísticos e inteligencia territorial: Respuestas ante la crisis. Actas del XIV Coloquio de Geografía, Turismo, Ocio y Recreación. (pp. 65-78). Sevilla: Universidades de Málaga y Sevilla.

Molz, J. G. (2012). Travel connections : tourism, technology and togetherness in a mobile world. London: Routledge.

Nam, T., \& Pardo, T. A. (2011). Conceptualizing smart city with dimensions of technology, people, and institutions. Proceedings of the 12th Annual International Digital Government Research Conference on Digital Government Innovation in Challenging Times - dg.o '11, (June), 282. http://doi.org/10.1145/2037556.2037602

OMT, \& ETC. (2005). El turismo urbano y la cultura - La experiencia europea. Madrid: Organización Mundial del Turismo \& Comisión Europea de Turismo.

Pearce, D. (2014). Destinos Turísticos: conceptos e implicaciones para su gestión en tiempos de cambio. En F. López Palomeque, G. Cánoves, A. Blanco Romero, \& A. Torres Delgado (Eds.), Turismo y territorio : innovación, renovación y desafios (pp. 21-34). Tirant Humanidades.

Pedersen, A. (2005). Gestión del turismo en sitios del Patrimonio Mundial: Manual práctico para administradores del sitios del Patrimonio Mundial. Recuperado a partir de http://unesdoc.unesco.org/images/0012/001286/128679s.pdf

Porter, M. E., \& Heppelmann, J. E. (2014). How smart, connected products are transforming competition. Harvard Business Review, 92(11), 64-88.

Rabari, C., \& Storper, M. (2015). The digital skin of cities: Urban theory and research in the age of the sensored and metered city, ubiquitous computing and big data. Cambridge Journal of Regions, Economy and Society, 8(1), 27-42. http://doi. org/10.1093/cjres/rsu021

Rodríguez Fernández, J. M. (2007). Responsabilidad social corporativa y análisis económico : práctica frente a teoría. Revista Ekonomiaz, $N^{\circ} 65,37$.

Schwab, K. (2016). La Cuarta revolución industrial. Debate. 
Actas del Seminario Internacional Destinos Turísticos Inteligentes:

nuevos horizontes en la investigación y gestión del turismo

Universidad de Alicante, 26 y 27 de octubre de 2017

Secretaría de Estado de Turismo. (2012). Plan Nacional e Integral de Turismo (PNIT) 2012-2015. Madrid.

SEGITTUR. (2016). Memoria Anual SEGITTUR 2015. Madrid.

Sheehan, L., Vargas Sánchez, A., Presenza, A., \& Abbate, T. (2016). The Use of Intelligence in Tourism Destination Management: An Emerging Role for DMOs. International Journal of Tourism Research, 18(6), 549-557. http://doi.org/10.1002/ jtr.2072

Sheldon, P. J. (1997). Tourism information technology. Tourism information technology. CAB INTERNATIONAL.

Tilden, F. 1883-1980. (2006). La interpretación de nuestro patrimonio. Asociación para la Interpretación del Patrimonio.

Townsend, A. M. (2013). Smart cities : big data, civic hackers, and the quest for a new utopia. New York: Norton. Recuperado a partir de http://cataleg.ub.edu/ record $=$ b2203272 S1* cat

UNESCO, \& UNWTO. (1998). Proceedings of the « Tourism Management in Heritage Cities ».

Wang, D., Park, S., \& Fesenmaier, D. R. (2012). The Role of Smartphones in Mediating the Touristic Experience. Journal of Travel Research, 51(4), 371-387. http://doi. org/10.1177/0047287511426341

World Heritage Centre. (2015). Policy for the Integration of a Sustainable Development Perspective into the Processes of the World Heritage Convention, 1-18. Recuperado a partir de http://whc.unesco.org/document/139146

Xiang, Z., \& Fesenmaier, D. R. (2017). Big Data Analytics in Smart Tourism Design. En Z. Xiang \& D. R. Fesenmaier (Eds.), Analytics in Smart Tourism Design (pp. 299-307). Cham: Springer International Publishing. http://doi.org/10.1007/9783-319-44263-1 